based on our fundamental belief in the dignity and equality of every human being and that he join us in seeking to combat the real causes of poverty and disease.

1 World Bank. The World Bank Atlas. Washington, DC: World Bank, 1989

Kirkman RVE, Morris J, Webb A. User's experience of Mates versus Neuroform. British fournal of Family Planning 1990;15:107-11.
3 Duncan G, Harper C, Ashwell E, Munt D, Buchan H, Jones L. Termination of pregnancy: lessons for prevention. British fournal of Family Planning 1990;15:112-7

4 Dowling E. Socio-educational model for the installation of a community-based NFP service delivery system in the rural Philippines. In: International Federation for Family Life Promotion. Abstracts of papers presented at the Federation for Family Life Promotion. Abstracts of papers presented at the IVth congress of the International Federation for Family Life Promotion,

Accepted 21 May 1990)

\title{
The effectiveness of two smoking cessation programmes for use in general practice: a randomised clinical trial
}

\author{
Karen Slama, Selina Redman, Janice Perkins, Alexander L A Reid, Robert W Sanson-Fisher
}

\begin{abstract}
Objective-To evaluate a structured, behavioural change, smoking cessation intervention designed for use within general practice.

Design-Randomised controlled clinical trial.

Setting-General practices in Newcastle, Australia.

Patients - 311 Patients identified as smokers by a screening question were entrolled in the study. Of these, 101 were assigned to a structured behavioural change programme, 104 to a simple advice programme adapted from previous research, and 106 to a control group. No significant differences were found between groups for demographic and smoking related variables before the study.

Interventions - Patients in the simple advice group received a brief statement of advice from the general practitioner as well as three pamphlets; those in the structured intervention group were given strategies which included attitude and behavioural change programmes as well as techniques to aid compliance. The amount of smoking in all groups was assessed by self reports with validation by measurement of salivary cotinine concentrations.
\end{abstract}

Main outcome measure-Significant increase in cessation rates.

Conclusions-Significant differences between controls and the structured behavioural change group were found at the one month follow up, but only for self reported abstinence. The simple advice programme did not produce any significant differences over the control group. General practitioner evaluation of the structured programme highlighted difficulties in relation to the duration of the intervention. Overall the structured programme in its present form did not appear to be an effective programme for use within general practice.

\section{University of Newcastle,}

Newcastle, New South

Wales, Australia 2308

Karen Slama, PHD, consultant in behavioural science in relation to medicine Selina Redman, PHD, senior lecturer in behavioural science in relation to medicine

Janice Perkins, BA, research assistant in behavioural science in relation to medicine

Alexander L A Reid,

FRACGP, associate professor of general practice

Robert W Sanson-Fisher, PHD, professor of behavioural science in relation to medicine

Requests for reprints and correspondence to:

Professor Sanson-Fisher.

Br.Med f 1990;300:1707-9 proportion of the population' and are a credible source with a plausible message to convey through personal contact. $^{2}$ Initial randomised clinical trials of brief interventions found that general practitioners' advice produced higher cessation rates than no advice. ${ }^{3}$ More recent trials, however, have not produced similar results. ${ }^{45}$ As physicians apparently often fail routinely to counsel their smoking patients ${ }^{67}$ more time and skilled effort may be needed by general practitioners if significant cessation rates are to be achieved. In line with this, multiple session programmes have produced better results than brief interventions, with up to $36 \%$ of patients reporting cessation at three years. ${ }^{8}$ Multisession programmes may not, however, be suitable for routine use because of the high expenditure of time required by the general practitioner. If smoking cessation programmes are to be widely adopted the costs in time and effort must be reduced as much as possible.

We performed a randomised clinical trial to compare a control group and a minimal intervention group with a group who received a more intensive smoking cessation programme oriented towards the individual. We hoped that the structured behavioural intervention would be more effective and also be acceptable for routine use by general practitioners.

\section{Subjects and methods}

Twenty three general practitioners from New South Wales who had expressed an interest in smoking cessation research were invited to take part in the study; $17(74 \%)$ agreed. Patients were approached while awaiting their consultation and were included if they were self reported smokers, were aged 18-64 years, and could read and speak English. Previous research had indicated that self reports about smoking corresponded closely with saliva cotinine concentrations.

Eligible consenting patients were asked to complete a questionnaire before the consultation. The questionnaire asked for demographic data and information on smoking behaviour. In addition, the questionnaire included questions concerning patients' health beliefs and fears about the costs of smoking cessation. Each participating doctor's patients were randomly assigned to no treatment, simple advice, or a brief tailored behavioural change programme. The general practitioner asked the patients for permission to audiotape the consultations.

The control group received no information or advice about smoking. The simple advice group received a statement of advice and three smoking cessation brochures similar to those used in previous research. ${ }^{3}$ The structured behavioural change intervention consisted of the components shown in table III. Nicotine gum was not prescribed to any participant. All patients were told that they might be contacted by the university later.

\section{MEASURES}

Cessation-Self reported smoking behaviour was measured in telephone or home based interviews conducted at one, six, and 12 months. Interviewers were unaware of the patient's group. Biochemical validation of self reported abstinence was performed using paired ion liquid chromatography analysis of salivary cotinine concentrations. Abstinence was considered to be validated if there was no detectable cotinine present $(<50 \mathrm{nmol} / \mathrm{l}) .{ }^{10}$

Acceptability-Audiorecordings of each consultation 
were timed by stopwatch to obtain information concerning the duration of both the intervention and the normal consultation. The recordings also allowed the general practitioners' adherence to the smoking cessation protocol to be assessed. General practitioners were asked to predict the impact of the intervention on each patient and to assess the behavioural programme. All participating patients were asked to indicate their expectations about being advised about smoking, whether or not they had disliked receiving advice, and their satisfaction with the specific information provided.

\section{GENERAL PRACTITIONER TRAINING}

An hour long training session included a description of the protocol for the trial, a detailed description and a videotaped demonstration of the behavioural programme, and open discussion. A dossier of background information was provided for further reference. Before the trial each general practitioner recorded a practice session of the behavioural programme, and a brief individual meeting was held to discuss any difficulties or omissions.

\section{Results}

Of the 1056 patients approached for inclusion in the study a screening question identified 359 smokers from the total number attending surgery (34\% prevalence). Nine of these were excluded by their doctors because of serious medical conditions, and seven were excluded because of incomplete pretest data. Thirty two patients were not included in the analysis because they could not be located for the first follow up. No patients refused to be audiotaped. The final sample size

TABLE I - Numbers (and percentages) of patients abstaining (with $95 \%$ confidence intervals of percentages) at one month, six months, and 12 months based on self reports and chemical validation

\begin{tabular}{|c|c|c|c|c|c|c|c|}
\hline & \multicolumn{2}{|c|}{ Control group } & \multicolumn{2}{|c|}{ Simple advice group } & \multicolumn{2}{|c|}{ Behavioural group } & \multirow[b]{2}{*}{$\begin{array}{l}\text { Significance of } \\
\text { difference }^{\star}\end{array}$} \\
\hline & $\begin{array}{l}\text { No in } \\
\text { group }\end{array}$ & $\begin{array}{c}\text { No (\%) } \\
\text { abstaining }\end{array}$ & $\begin{array}{l}\text { No in } \\
\text { group }\end{array}$ & $\begin{array}{c}\text { No (\%) } \\
\text { abstaining }\end{array}$ & $\begin{array}{l}\text { No in } \\
\text { group }\end{array}$ & $\begin{array}{c}\text { No (\%) } \\
\text { abstaining }\end{array}$ & \\
\hline \multicolumn{8}{|c|}{ Self reported abstinence: } \\
\hline 1 month & 106 & $\begin{array}{c}10(9) \\
(3 \text { to } 14)\end{array}$ & 104 & $\begin{array}{c}15(14) \\
(8 \text { to } 21)\end{array}$ & 101 & $\begin{array}{c}19(19) \\
(11 \text { to } 26)\end{array}$ & $\begin{array}{c}\gamma_{\hat{\mathrm{i}} .}=4 \cdot 64 \\
\mathrm{p}=0.03\end{array}$ \\
\hline 6 months & 106 & $\begin{array}{l}12(11) \\
(5 \text { to } 17)\end{array}$ & 104 & $\begin{array}{l}12(11) \\
(5 \text { to } 17)\end{array}$ & 101 & $\begin{array}{c}18(18) \\
(10 \text { to } 25)\end{array}$ & $\begin{array}{c}\chi_{\hat{i}}^{2}=1 \cdot 87 \\
p=0 \cdot 17\end{array}$ \\
\hline 12 months & 106 & $\begin{array}{c}12(11) \\
(5 \text { to } 17)\end{array}$ & 104 & $\begin{array}{c}11(10) \\
(3 \text { to } 14)\end{array}$ & 101 & $\begin{array}{c}17(17) \\
(10 \text { to } 24)\end{array}$ & $\begin{array}{c}\gamma_{\mathrm{i} .}^{2}=1.42 \\
\mathrm{p}=0.23\end{array}$ \\
\hline $\begin{array}{l}\text { Validated abs } \\
1 \text { month }\end{array}$ & 104 & $\begin{array}{c}2(2) \\
(-1 \text { to } 5)\end{array}$ & 97 & $\begin{array}{c}2(2) \\
(-1+5)\end{array}$ & 92 & $\begin{array}{c}7(8) \\
(2 \text { to } 13)\end{array}$ & $\begin{array}{c}\text { Control } v \text { simple } \mathrm{p}>0 \cdot 1 \\
\text { control } v \text { behavioural } \\
\mathrm{p}=0.07 t\end{array}$ \\
\hline 6 months & 104 & $\begin{array}{c}6(6) \\
(1 \text { to } 10)\end{array}$ & 103 & $\begin{array}{c}7(7) \\
(2 \text { to 12) }\end{array}$ & 99 & $\begin{array}{l}12(12) \\
(6 \text { to } 19)\end{array}$ & $\begin{array}{c}\chi_{\mathrm{i}}=2 \cdot 70 \\
\mathrm{p}=0 \cdot 10\end{array}$ \\
\hline 12 months & 106 & $\begin{array}{c}8(8) \\
(3 \text { to } 13)\end{array}$ & 104 & $\begin{array}{c}5(5) \\
(1 \text { to } 9)\end{array}$ & 101 & $\begin{array}{l}12(12) \\
(6 \text { to } 18)\end{array}$ & $\begin{array}{c}\gamma_{\mathrm{L}}^{2}=1 \cdot 27 \\
\mathrm{p}=0 \cdot 26\end{array}$ \\
\hline
\end{tabular}

$\chi_{\chi i}$ is $\chi^{2}$ test for linear trend.

tOne month validated results were tested using Fisher's exact test because of small expected frequencies.

TABLE II -Numbers and (percentages) of patients who were consecutively abstinent based on self reports and chemical validation (with $95 \%$ confidence intervals of percentages)

\begin{tabular}{|c|c|c|c|c|c|}
\hline & \multirow[b]{2}{*}{$\begin{array}{l}\text { Control group } \\
(\mathrm{n}=106)\end{array}$} & \multirow[b]{2}{*}{$\begin{array}{l}\text { Simple advice } \\
\text { group }(n=104)\end{array}$} & \multirow[b]{2}{*}{$\begin{array}{l}\text { Behavioural group } \\
\qquad(\mathrm{n}=101)\end{array}$} & \multicolumn{2}{|c|}{ Fisher's exact test ${ }^{\star}$} \\
\hline & & & & $\begin{array}{l}\text { Control } v \\
\text { simple }\end{array}$ & $\begin{array}{l}\text { Control } v \\
\text { behavioural }\end{array}$ \\
\hline \multicolumn{6}{|l|}{ Self reports: } \\
\hline $\begin{array}{l}\text { Patients abstinent } \\
\text { at } 1 \text { and } 6 \text { months }\end{array}$ & $\begin{array}{c}1(1) \\
(-1 \text { to } 3)\end{array}$ & $\begin{array}{c}3(3) \\
(0 \text { to } 6)\end{array}$ & $\begin{array}{c}7(7) \\
(2 \text { to } 12)\end{array}$ & $>0 \cdot 1$ & $>0.028$ \\
\hline $\begin{array}{l}\text { Patients abstinent } \\
\text { at } 1,6 \text {, and } 12 \text { months }\end{array}$ & $\begin{array}{c}1(1) \\
(-1 \text { to } 3)\end{array}$ & $\begin{array}{c}2(2) \\
(-1 \text { to } 5)\end{array}$ & $\begin{array}{c}6(6) \\
(1 \text { to } 11)\end{array}$ & $>0 \cdot 1$ & 0.052 \\
\hline \multicolumn{6}{|l|}{ Validated: } \\
\hline $\begin{array}{l}\text { Patients abstinent } \\
\text { at } 1 \text { and } 6 \text { months }\end{array}$ & $\begin{array}{c}1(1) \\
(-1 \text { to } 3)\end{array}$ & $\begin{array}{c}1(1) \\
(-1 \text { to } 3)\end{array}$ & $\begin{array}{c}6(6) \\
(1+11)\end{array}$ & $>0 \cdot 1$ & $0 \cdot 052$ \\
\hline $\begin{array}{l}\text { Patients abstinent at } \\
1,6 \text {, and } 12 \text { months }\end{array}$ & $\begin{array}{c}1(1) \\
(-1 \text { to } 3)\end{array}$ & $\begin{array}{c}1(1) \\
(-1 \text { to } 3)\end{array}$ & $\begin{array}{c}5(5) \\
(1 \text { to } 9)\end{array}$ & $>0 \cdot 1$ & 0.095 \\
\hline
\end{tabular}

$\star$ One tailed probability.
TABLE III-Percentage of general practitioners who used various components of the structured behavioural change intervention protocol

\begin{tabular}{lc}
\hline Protocol component & \% Who used component \\
\hline Attitude change & 91 \\
Diseases and smoking & 97 \\
Risks of smoking & 95 \\
Risk appraisal & 89 \\
Benefits of cessation & 80 \\
Self efficacy & 56 \\
Reassurance about fears & 80 \\
Confidence boosting & 46 \\
Persistence stressed & 42 \\
Behavioural aids & 82 \\
Contracting & 90 \\
Avoiding cues to smoke & 88 \\
Cold turkey & 86 \\
Attention to immediate benefits of cessation & 78 \\
Encouraging social support & 70 \\
Communication aids & 48 \\
Written reinforcement (pamphlets) & 99 \\
Warmth and commitment & 45 \\
Naming areas to be discussed & 35 \\
Summarising information & 13 \\
\hline
\end{tabular}

consisted of 311 smokers: 106 controls, 104 in the simple advice group, and 101 in the behavioural change programme. No significant differences were found between groups in demographic or smoking related variables.

Motivation-No significant differences in health beliefs were found in any group between the pretest questionnaire and one month follow up, except on one item: the perceived general risk of smoking changed significantly in the behavioural group (repeated measures analysis of variance $F$ value $7 \cdot 99, p<0.01$ ). Within the behavioural group $61 \%$ signed a contract to stop smoking.

Abstinence at each follow up point-At one month follow up $57 \%$ of the behavioural group reported they had tried to stop smoking. A significant difference in self reported cessation rates was found between the three groups at the one month but not at subsequent follow ups (table I). For biochemically validated abstinence, a one tailed Fisher's exact test showed a significant difference at one month between the control and behavioural groups but not between the control and simple advice groups. Linear trend $\chi^{2}$ analysis showed no significant differences between the groups at six or 12 months.

Consecutive abstinence - Cessation rates for consecutively abstinent smokers were calculated only from those patients who could be biochemically validated as non-smokers at the three follow up points. Patients who could not be validated as abstinent at one month because they provided too few samples, used nicotine gum, or could not attend for measurement at the appropriate times were regarded as abstinent only if they were subsequently validated at six and 12 month follow ups. Patients whose smoking status could not be validated in this way were counted as smokers. Table II shows the proportion of smokers who maintained abstinence over one and six months and over one, six, and 12 months. Differences between the control and simple advice groups and between the control and behavioural groups were assessed using the one tailed Fisher's exact test. Differences between the control and simple advice groups for both the self reported and validated measures did not reach significance $(\mathrm{p}>0 \cdot 1)$. For both time periods, however, and for both the self reported and validated measures the differences between the control and behavioural groups approached significance.

General practitioners' adherence to protocol-Table III indicates the use the doctors made of the components in the behavioural programme. The health beliefs and behavioural aids components were used in most interventions, but only half included self efficacy enhancements, and, except for handing out brochures, only a 
third of the presentations contained any other communication aids.

Duration - The general practitioners took an average of 8.8 minutes (SD 3.3 minutes) to present the structured behavioural intervention. The total time spent with smokers, however, was only 8.7 minutes longer than the average consultation time in the control group (9.0 minutes $(5 \cdot 6)$ ). The simple advice intervention took 1.4 minutes $(0.7)$, and total time averaged $0 \cdot 12$ minute longer than the average control consultation.

General practitioner satisfaction-At the completion of the study general practitioners felt they were successful with $45 \%$ of the behavioural programme group and $29 \%$ of the simple advice group but rated $43 \%$ of the behavioural interventions and $13 \%$ of the simple interventions as too long. After the trial half the doctors said they would use a smoking cessation programme with their smokers routinely.

Patient satisfaction-About half of the total sample of patients thought that their doctors should give them advice about their smoking. About $80 \%$ did not disapprove of their doctor's suggesting they stop smoking. The behavioural group indicated significantly greater satisfaction about the information given about the diversity of smoking related diseases (analysis of variance $F$ value $4.63, p<0.05$ ) and greater approval at receiving suggestions on how to stop smoking $\left(\chi^{2}=\right.$ $6.93, \mathrm{p}<0.01)$. No other significant differences between groups were found.

\section{Discussion}

The results of this study indicated that neither simple advice nor a structured behavioural change intervention resulted in a statistically significant increase in the number of patients stopping smoking long term relative to the control group. Validated cessation rates indicated that only $5 \%$ of patients in the structured group remained abstinent for 1? months. The effort needed by the general practitioner to learn the behavioural intervention programme and the costs of eight minutes per patient do not seem to justify recommending use of the programme over simple advice.

There was, however, some evidence that the structured behaviour change programme was more effective in motivating patients to stop smoking in the short term. In the month after the consultation $57 \%$ of the smokers in the behavioural group reported that they tried to stop smoking compared with $35 \%$ in the simple advice and $26 \%$ in the control group. Given that nicotine causes a true physiological dependence ${ }^{11}$ general practitioners may need to provide follow up sessions for their patients if cessation is to be maintained long term.

Overall half the general practitioners said that they were prepared to use the behaviour change intervention routinely. This finding is encouraging as it suggests that at least half of the respondents found the programme acceptable. Perhaps the most disappointing finding, however, was that $43 \%$ said that the programme was too long to implement routinely. Many smoking cessation programmes which have resulted in significant reductions in smoking rates have invariably been multisession programmes taking much longer periods. These findings suggest that if general practitioners are to realise their potential in helping patients to stop smoking either very brief but effective interventions will need to be developed or general practitioners will need to revise their priorities in care to allow more time for preventive interventions. Such revisions may necessitate the restructuring of time within general practice to accommodate these changes. An antismoking intervention such as this takes no longer, however, than other preventive procedures such as smears for cervical cancer. Once the backlog of patients generated by this change has been dealt with the continuing load would be moderate.

1 Australian Bureau of Statistics. Australian health survey 1977-78, doctor consultations. Canberra: Australian Bureau of Statistics, 1980. (Catalogue No 4319.0 .

2 Cockburn J, Killer D, Campbell E, Sanson-Fisher RW. Measuring general practitioners' attitudes towards medical care. Fam Pract 1987;4: 192-9.

3 Russell MAH, Wilson C, Taylor C, Baker CD. Effect of general practitioner's advice against smoking. Br Med $\mathcal{f}$ 1979;ii:231-5.

4 Stewart PJ, Rosser WW. The impact of routine advice on smoking cessation from family physicians. Can Med Assoc $\mathcal{F}$ 1982;126:1051-4.

5 Russell MAH, Stapleton JA, Jackson PH, Hajek P, Belcher M. District programme to reduce smoking: effect of clinic supported brief intervention by general practitioners. Br Med f 1987;295:1240-4.

6 Chu FZ, Day RG. Smoking recognition by family physicians. $f$ Fam Prac 1981;12:657-60

7 Fleming DM, Lawrence MSTA. An evaluation of recorded information about preventive measures in 38 practices. $\mathcal{F} R$ Coll Gen Pract 1984;31:615-20.

8 Richmond RL, Austin A, Webster IW. Three year evaluation of a programme by general practitioners to help patients to stop smoking. Br Med $\mathcal{J}$ by general prac $292: 803-6$.

9 Dickinson JA, Wiggers J, Leeder SR, Sanson-Fisher RW General practitioners' detection of patients' smoking status. Med I A ust 1989;150:420-6.

ttioners' detection of patients' smoking status. Med f Ausl 1989;150:420-6.
10 Jarvis MJ, Tunstall-Pedoe H, Feyerabend C, Vessey C, Saloojec Y. Comparison of tests used to distinguish smokers from nonsmokers. Am J Public Health $1987 ; 77: 1435-8$

11 Benowitz NC. Pharmacologic aspects of cigarette smoking and nicotine addiction. $N$ Engl f Med 1988;20:1318-30.

(Accepted 16 March 1990)

\section{MEDICINE AND THE MEDIA}

$\mathrm{BBC} 1$ Life on One

\section{Here's one I investigated earlier}

Picture, if you will, Sarah Greene, late of Blue Peter, standing outside a Birmingham public house with a jar of exhaled cigarette smoke in her hand. Before you can say, "And here is one I made earlier," there she is inside the pub discussing parts of carbon monoxide per million with former Radio 1 disc jockey Simon Mayo and a man he calls Mr Smoketoo-much. This is BBC l's new popular science programme, Life on One.
Popular I think it will be. Taking Thursday's $8 \mathrm{pm}$ slot while Tomorrow's World is on holiday, it aims at presenting current scientific, medical, and environmental issues "without wall to wall seriousness." From passive smoking to baldness, from bottle nosed dolphins to refrigerators and CFCs, it offers information and opinion well sprinkled with humour. But for all its "pop" presentation, up beat music, and punchy subtitles the programme has a hard campaigning edge.

Sarah and Simon lead a team of investigative reporters, attractive and female to a man, who seek out the stories, chase the guilty, and expose the absurdities of government and company policies. Strange it is that after quite appalling scenes showing dumping of waste in the North Sea by British Coal I felt almost optimistic. Call me naive, but Nikki Spencer's youthful energy and spirited inter- rogation of the man from the National Rivers Authority made me feel that something would actually be done about it.

Back in the pub Simon is on first name terms with Dr Martin Jarvis from the Imperial Cancer Research Fund and is asking what is being done about passive smoking; Sarah is out on the streets canvassing the views of the good burghers of Birmingham; and a telephone poll concludes that most viewers (who expressed a preference) think that smoking in public places should be banned.

Executive producer David Patterson plans to report back on stories if changes in policy occur. Armchair activists will like this series very much.-FIONA GODLEE, editorial registrar, $B M \mathcal{F}$ 